\title{
Enzyme-Linked Immunosorbent Assay for Screening of Canine Brucellosis Using Recombinant Cu-Zn Superoxide Dismutase
}

\author{
Ganbat TSOGTBAATAR ${ }^{1)}$, Masato TACHIBANA ${ }^{1)}$, Kenta WATANABE ${ }^{1)}$, Suk KIM $^{2)}$, Hiroshi SUZUKI ${ }^{3)}$ and \\ Masahisa WATARAI ${ }^{1) *}$ \\ ${ }^{1)}$ Department of Applied Veterinary Science and ${ }^{3)}$ Research Center for Protozoan Diseases, Obihiro University of Agriculture and \\ Veterinary Medicine, Obihiro, Hokkaido 080-8555, Japan and ${ }^{2}$ Laboratory of Public Health, College of Veterinary Medicine, \\ Gyeongsang National University, 900 Gajwa-Dong, Jinju, Gyeongnam 600-701, South Korea
}

(Received 3 February 2008/Accepted 18 August 2008)

ABSTRACT. Brucella canis, a facultative intracellular pathogen, is the causative agent of canine brucellosis. The diagnosis of canine brucellosis is based on bacteriological examination and serological methods including agglutination and gel diffusion tests. In this study, recombinant $B$. canis $\mathrm{Cu}-\mathrm{Zn}$ superoxide dismutase (SOD) was used as an antigen for the enzyme-linked immunosorbent assay (ELISA). The recombinant SOD showed a specific reaction with serum infected with B. canis in Western blotting and ELISA. These results suggest that ELISA using recombinant SOD is useful in screening for canine brucellosis.

KEY WORDS: brucellosis, $\mathrm{Cu}-\mathrm{Zn}$ superoxide dismutase, ELISA.

Canine brucellosis is widely distributed around the world and is an important disease due to the economic losses it causes in animal production, and the risks to human health [7]. Reproductive disorders, such as abortions and premature births, are the clinical signals of this bacterial disease in pregnant animals. Diagnosis of the disease is based on bacteriological examination and serological tests [4]. Serological diagnosis is usually performed by the tube agglutination test, rapid slide agglutination test, and gel immunodiffusion test [4-6]. However, agglutination tests sometimes give false-positive reactions due to cross-reactions with other pathogens, and a general strategy for eliminating such crossreactions is to use purified antigen with unique epitopes. We previously reported that a method in which crude hot saline extracted antigens are coated on to latex beads would be useful in the serological diagnosis of canine brucellosis [12]. Among the antigens extracted in this way, $\mathrm{Cu}-\mathrm{Zn}$ superoxide dismutase (SOD) showed the strongest antigenic reaction [12]. In the present paper, we report a screening method for canine brucellosis using an enzyme-linked immunosorbent assay (ELISA) with recombinant SOD as antigen.

The gene encoding SOD was amplified from chromosomal DNA isolated from $B$. canis by means of PCR with 5'-GTGATGAAGTCCTTATTTATT-3' and 5'-TTATTCGATCACGCCGCAGGC-3' used as the pair of primers. The product was cloned into pCold TF vector (Takara Bio Inc., Shiga, Japan). The trigger factor (TF) and His-tagged SOD was expressed in the E. coli strain DH5 $\alpha$, and its purification was performed as described by the manufacturer (Novagen, Darmstadt, Germany). The antigen solution was separated using $10 \%$ SDS-PAGE and then transferred to

\footnotetext{
* Correspondence to: Watarai, M., Department of Veterinary Public Health, Faculty of Agriculture, Yamaguchi University, 1677-1 Yoshida, Yamaguchi 753-8515, Japan.

e-mail:watarai@yamaguchi-u.ac.jp
}

Immobilon-P membranes (Millipore, Billerica, MA, U.S.A.). The efficiency of transfer was determined using Coomassie brilliant blue R-250, and then the membranes were tested for reactivity with antibodies in canine sera. The tube agglutination test was performed as follows. Heatinactivated B. canis QE-13 whole-cell antigens were obtained from Kitasato Laboratories. Equal volumes (0.5 $\mathrm{m} l$ ) of the whole-cell antigens (optical density of 0.8 at 450 $\mathrm{nm}$ ) and serum, which had been serially diluted 2-fold with PBS, were incubated at $50^{\circ} \mathrm{C}$ for $24 \mathrm{hr}$. Agglutination titers were determined from the final dilution of serum showing $50 \%$ agglutination. Samples showing a titer higher than 160 were considered to be positive [3, 10]. ELISA using recombinant SOD was performed as follows. To coat the recombinant SOD onto immunoplates for ELISA, $50 \mu l$ of it (50 $\mu \mathrm{g} / \mathrm{m} l$ ) was added to a 96-well Immuno plate (Nunc, Rochester, NY, U.S.A.) and left overnight at $4^{\circ} \mathrm{C}$. Then, the wells were blocked using $0.5 \%$ bovine serum albumin (BSA) for $30 \mathrm{~min}$. Sera diluted $1 / 200$ were added to the wells. The wells were incubated at $37^{\circ} \mathrm{C}$ for $1 \mathrm{hr}$, were washed, and then horseradish peroxidase-labeled anti-dog IgG (Santa Cruz Biotechnology, Santa Cruz, CA, U.S.A.) was added. The wells were incubated at $37^{\circ} \mathrm{C}$ for $1 \mathrm{hr}$, were washed, and a substrate, 3,3',5,5'-tetramethylbenzidine (TMB) liquid substrate system for ELISA (SIGMA, St. Louis, MO, U.S.A.), was added. The absorbance was measured at $405 \mathrm{~nm}$ by an ELISA reader (model 450, Bio-Rad, Hercules, CA, U.S.A.).

To identify sera infected with B. canis, we performed the tube agglutination test on canine serum samples $(n=224)$ randomly selected from dogs consecutively admitted to animal hospitals in Korea by hospital staff. In the test, antibodies to B. canis were detected in 30 of the 224 serum samples (Table 1). Recombinant SOD was subjected to Western blotting together with dog serum that had tested positive and negative in the tube agglutination test to test for antigenic 
Table 1. Serological analysis of canine sera

\begin{tabular}{llllllc}
\hline & \multicolumn{2}{c}{$\mathrm{TAT}^{\mathrm{a})}+30(13.4 \%)$} & & \multicolumn{2}{c}{ TAT- $194(86.6 \%)$} \\
\cline { 2 - 3 } \cline { 5 - 6 } \cline { 5 - 6 } Sera $(\mathrm{n}=224)$ & ELISA $^{\mathrm{b})}+$ & ELISA- & & ELISA+ & ELISA- \\
\cline { 2 - 3 } $\mathrm{WB}^{\mathrm{c}}+$ in ELISA+ & $30(100 \%)$ & $0(0 \%)$ & & $2(1.0 \%)$ & $192(99.0 \%)$ \\
& $26(86.7 \%)$ & - & & $0(0 \%)$ & -
\end{tabular}

a) Tube agglutination test.

b) Samples with absorbance values of over $0.400\left(\mathrm{OD}_{405}\right)$.

c) Western blot analysis.

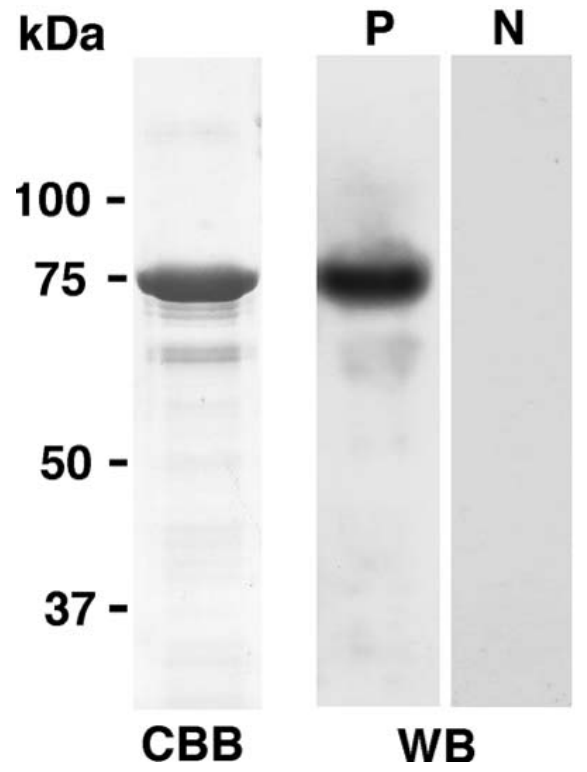

Fig. 1. Western blot analysis of recombinant SOD. TF fusion SOD was separated by SDSPAGE under reduced condition and then transferred to nylon membranes. The membranes were stained with Coomassie brilliant blue (CBB) and used for analysis of B. canis infected $(\mathrm{P})$ and uninfected $(\mathrm{N})$ sera $(\mathrm{WB})$.

reactivity. The recombinant SOD showed strong reactivity with positive sera, but not with negative sera (Fig. 1). These results indicated that the recombinant SOD reacted specifically with Brucella infected sera. We then determined whether ELISA using recombinant SOD can be applied to screening for canine brucellosis using the dog serum samples from Korea. All serum samples having absorbance values of over 0.410 or under $0.400\left(\mathrm{OD}_{405}\right)$ were either positive or negative in the tube agglutination test (Fig. 2). Six serum samples having an absorbance value between 0.410 and $0.401\left(\mathrm{OD}_{405}\right)$ produced a mixed result, and the tube agglutination test detected antibodies to $B$. canis in 4 of them (Fig. 2). Immunoreactive bands were detected for sera having an absorbance value of over $0.41\left(\mathrm{OD}_{405}\right)$ in Western blotting (Table 1). Thus, the absorbance measurements in ELISA with recombinant SOD and the titers in the tube agglutination test showed a similar tendency, suggesting that ELISA with recombinant SOD is useful in screening for canine brucellosis. However, for the serum samples having low absorbance values of around 0. $400\left(\mathrm{OD}_{405}\right)$, it was difficult to judge whether they were positive or negative for canine brucellosis.

The tube agglutination test using whole $B$. canis antigens has been used to diagnose brucellosis in dogs in Japan [10]. However, it has been noted that nonspecific reactions occur in a tube agglutination test using whole bacterial cell antigens as well as in the rapid slide agglutination test [2]. More recently, with the aim of developing a serological diagnosis method that is easier to perform, we coated latex beads with antigens extracted by hot saline for use in the agglutination test [12]. However, the crude antigens extracted in our method were not specific ones and therefore not useful in a highly sensitive serodiagnosis method such as ELISA [12]. Since SOD is a known antigenic protein of B. abortus [1], its potential value as a vaccine for brucellosis prevention and as a diagnostic reagent for the disease has been investigated [8, $9,11]$, and the results in our study showed that recombinant SOD was useful for the detection of canine brucellosis. Further, since ELISA can be used for very small serum samples and handle many samples at a time, it would be suitable for the screening of valuable samples such as those from wildlife or small animals. Besides, conventional serological and bacteriological tests would be needed to diagnose for canine brucellosis.

\section{REFERENCES}

1. Bricker, B. J., Tabatabai, L. B., Judge, B. A., Deyoe, B. L. and Mayfield, J. E. 1990. Cloning, expression, and occurrence of the Brucella $\mathrm{Cu}-\mathrm{Zn}$ superoxide dismutase. Infect. Immun. $\mathbf{5 8}$ : 2935-2939.

2. Corbel, M. J. 1985. Recent advances in the study of Brucella antigens and their serological cross-reactions. Vet. Bull. 55: 927-942.

3. Erdenebaatar, J., Bayarsaikhan, B., Watarai, M., Makino, S. and Shirahata, T. 2003. Enzyme-linked immunosorbent assay to differentiate the antibody responses of animals infected with Brucella species from those of animals infected with Yersinia enterocolitica O9. Clin. Diagn. Lab. Immunol. 10: 710-714.

4. Flores-Castro, R. and Carmichael, L. E. 1978. Canine brucellosis: Current. Status of methods for diagnosis. Cornell Vet. 68: 76-88.

5. George, L. W. and Carmichael, L. E. 1974. A plate agglutination test for the rapid diagnosis of canine brucellosis. Am. J. Vet. Res. 35: 905-909.

6. Myers, D. M., Varela-Diaz, V. M. and Coltorti, E. A. 1974. Comparative sensitivity of gel-diffusion and tube agglutination tests for the detection of Brucella canis antibodies in experi- 


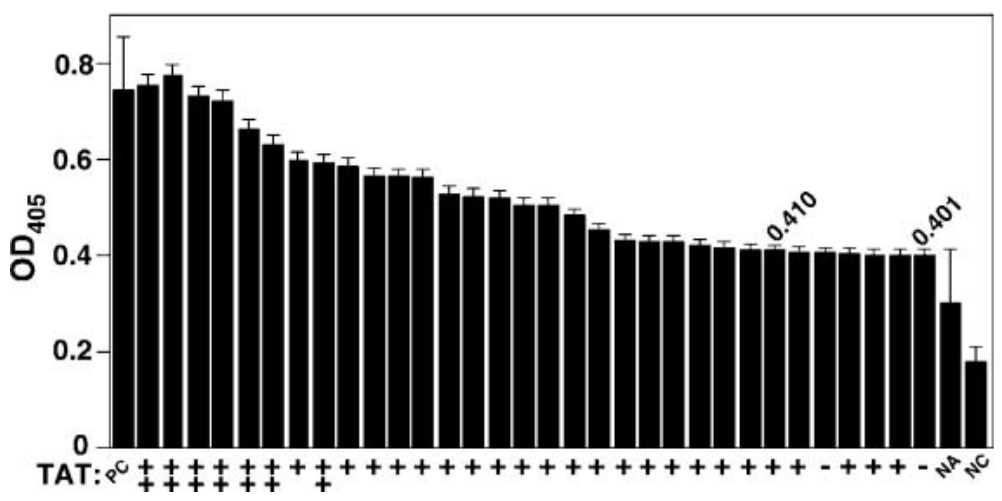

Fig. 2. ELISA absorbance values of dog sera using recombinant SOD. The bars indicate samples with absorbance values of over $0.400\left(\mathrm{OD}_{405}\right)$. Values are averages and standard deviations of triplicate wells from three identical experiments. PC, NC and NA indicate average absorbance value of ten positive control (infected) sera, ten negative control (uninfected) sera and the tube agglutination test negative sera (194 samples). Titers for the tube agglutination test (TAT) with B. canis antigen are indicated as $-(<1: 80),+(1: 160)$, and $++(1: 320)$, respectively.

mentally infected dogs. Appl. Microbiol. 28: 1-4.

7. Nielsen, K. H. and Duncan, J. R. 1990. Animal Brucellosis. CRC Press, Boca Raton.

8. Onate, A. A., Vemulapalli, R., Andrews, E., Schurig, G. G., Boyle, S. and Folch, H. 1999. Vaccination with live Escherichia coli expressing Brucella abortus $\mathrm{Cu} / \mathrm{Zn}$ superoxide dismutase protects mice against virulent $B$. abortus. Infect. Immun. 67: 986-988.

9. Onate, A. A., Cespedes, S., Cabrera, A., Rivers, R., Gonzalez, A., Munoz, C., Folch, H. and Andrews, E. 2003. A DNA vaccine encoding $\mathrm{Cu}, \mathrm{Zn}$ superoxide dismutase of Brucella abortus induces protective immunity in $\mathrm{BALB} / \mathrm{c}$ mice. Infect. Immun.
71: $4857-4861$.

10. Serikawa, T., Muraguchi, T. and Nakano, N. 1977. A survey of dogs from Gifu and Shiga area for Brucella canis. Jpn. J. Vet. Sci. 39: 635-642.

11. Tabatabai, L. B. and Hennager, S. G. 1994. Cattle serologically positive for Brucella abortus have antibodies to B. abortus $\mathrm{Cu}-$ Zn superoxide dismutase. Clin. Diagn. Lab. Immunol. 1: 506510.

12. Watarai, M., Kim, S., Yamamoto, J., Miyahara, K., Kazama, M., Matsuoka, S., Chimura, S. and Suzuki, H. 2007. A rapid agglutination assay for canine brucellosis using antigen coated beads. J. Vet. Med. Sci. 69: 477-480. 